\title{
Are 2020's Social Movements Proof of the End of Globalization?
}

\author{
Dumitru Alexandru Bodislav ${ }^{1, *}$, Marcela Antoaneta Niculescu $^{2}$, and Carmen Valentina \\ Rădulescu ${ }^{1}$ \\ ${ }^{1}$ Bucharest University of Economic Studies, Romana Square, no. 6, Bucharest, Romania \\ ${ }^{2}$ National Institute of Research and Development for Industrial Ecology, Drumul Podu Damvobvitei \\ St. 71-73, Bucharest, Romania
}

\begin{abstract}
.
Research background: This paper is targeted towards the concept of globalization, its limits and how today's social movements are proof of a new path needed for sustainable development, sustainability as a goal, economic growth as social progress and the need for taking care of all nationalities, all types of countries when it comes to their development (emerging versus developed) and importing the American's Navy principle, "No man left behind", in this case from a social and economic perspective, because we try to highlight that today's protests and riots are actually based on the need to be listened on the issues they have, each economy having different issues for its population and these vary from LGBT issues, Black Lives Matter, All Lives Matter and anti-corruption movements. The paper analysis 2020 's social movements and the double standards of social development depending on the types of economies we observe.

Purpose of the article: The paper represents on overview of the social movements in 2020.

Methods: The research is based on fundamental analysis of the news that feed social movements and the technical approach of their economic results.

Findings \& Value added: The paper offers the big picture on how the economy develops in line with its social movements and also targeting the need for a clear future.
\end{abstract}

Keywords: globalization; social movements; sustainable development; economic growth; riots

JEL Classification: $P 2 ; F 62 ; F 63$

\footnotetext{
*Corresponding author: alex.bodislav@,ase.ro
} 


\section{Introduction}

Even before the widespread spread of media and digital technologies, theories about their impact on everyday life, especially social relations, emerged. The book "Digital Generation and Media Addiction" by Valkenburg and Piotrowski [1] even draws attention to the exaggerations of such studies, giving the example of a 1998 study by Robert Kraut which showed that the use of social media would lead to a number less social ties and more loneliness for people who used this means of communication. In the years of the study, the two authors noted, adolescents' access to computers was about 11 percent in the United States, and digital communications were reduced to anonymous chat rooms and newsgroups, most often used to share information and personal experiences. For example, the number of people connected to the Internet globally increased from 0.4 billion in 2000 to 3.5 billion in 2016; Facebook surpassing 2 billion users.

The example above shows not only the exaggeration of some studies that precede the analysed situation, but also the exponential degree of global spread of these technologies and means of digital communication. The integration of such a volume of technologies into the daily life of mankind as a whole can only change the social structure and human interactions, especially since the Internet is a means of communication.

Marshall McLuhan notes that "the environment is the message" [2], a fact "characteristic of all media means that for any medium 'content' is a different medium". Developing this idea, it is understood that the informational content of the message is the result of the influence and pressure of an external environment (group) of thinking, with its own unique features, resulting from common information and experiences, as well as own, special, assembled in a unique formula.

Depending on the hierarchy of values, information and interests of each individual.

Through messages, ideas, experiences, values and interests are exchanged. In practical studies conducted in recent years it has been noted based on scientific models (especially after the development of psychology, sociology and branches of economics such as behavioural economics and identity economics) that messages that promote ideas, experiences, values and interests common to the sender, creates a connection of the receiver with the sender of those messages.

Also, in recent years, using scientific models, in many cases at the national level, it has been practically determined that the use of a limited number of elements of individual identity can lead to a marginal change or even longer-term alteration of behaviour, in many cases, contract of direct interests, of the values publicly displayed and accepted, but also of the interpretations of the ideas formed and of the lived experiences.

In this situation we can talk about workers or employers who voted for Brexit, although their direct interest was access to the European market, British farmers using European subsidies and cheap labour of EU immigrants, simple consumers who often benefited from low cost products and services provided by immigrants with salaries lower than the national average or even assistance benefiting from public revenues from immigrant contributions (taxes) or guaranteed universal public health services in the context of the United Kingdom's membership of the European Union.

In specific cases, opposing identity elements (interests) may coexist in the electoral platform of a single party, as in the case of the 5 Star Movement in Italy which has different, often contradictory, proposals, depending on the region in which the campaign takes place, and even in depending on each candidate.

Meanwhile, across the Atlantic Ocean, Donal Trump's election campaign focused on exacerbating common identities and identifying voters whose interests were threatened by the Republican candidate, such as African Americans, Hispanics or the middle-income or financially dependent state subsidies or allocations (e.g., Earned Income Tax Credit) with 
personalized messages sent to each individual, highlighting common identities with Trump, thus minimizing other identities that would make those voters outsiders and discriminated against in reprisals group benefits.

The choice of this topic was due to the purpose of understanding the new social realities demonstrated by the examples given and the new studies and scientific models developed and tested practically following developments in various fields of empirical research such as psychology, sociology, identity economics and behavioural. Also, to understand the new social realities, but also its evolution, at least in the short and medium term it was necessary to document the evolution of technology and its impact on society, through elements such as the impact of technology on the economy, the impact of identity on the economy and the impact the development of digital social networks and technology in general at the level of human identity and the emergence of new identity concepts such as digital identity and the concept of fluid identities.

\section{Research background - the evolution of social networks}

The need of group people appears as a subconscious, ancestral need, observed in several species. This need arises for the protection of external threats from other species or from the same species and for the diversification of tasks or the area of activity (for example, covering a larger area of hunting, gathering or planting).

With the evolution of the species, humans have noticed the benefits of belonging to a group, later expanded, due to increased access to larger resources, but still limited to the primary needs of individuals.

Over time, through the horizontal development of groups to limits difficult to control by the community, without increasing the consumption of additional resources, there is a need to develop elements to identify the members of the group to preserve welfare, limit the distribution of benefits and avoid unsustainable growth resources for monitoring group members, which could have become an internal threat to members or to the group as a whole, during periods of reduced benefits due to adverse weather conditions, depreciation of capital held by the group (depletion of land resources) or natural resource constraints in the context of expanding human needs either horizontally (population growth) or vertically (emancipating the needs and desires of individuals, such as more food, less work, better living conditions for both active and passive members of group) [3].

In the case of Europe, the use of ancient intellectual resources in the fourteenth and sixteenth centuries, marking the Renaissance, after a period in which needs exceeded available resources and characterized by an inefficient administrative system, led to economic and social development. The Renaissance was a period in which there was a transition from medieval to modern society. The first elements of this transition were defined as the development of trade in Italy, increasing the economic resources of the bourgeoisie and marginally emancipating the peasantry in the interest of the above. In the book "A History of Childhood" [4], reference is made to the effects of this economic development and through it to the change of the medieval Christian mentality. In that period of relative well-being, the bourgeoisie had begun to invest in children's education with the idea of exploiting children's future skills in family businesses, in old age, when they would receive dividends from their children's work. The same pattern was observed within the peasant groups, although in both groups there was still discrimination based on sex, however, the increase in the volume of resources in the general society led to a decrease in infanticide compared to the previous period, especially in areas who benefited more from the newly created welfare. 
In the context of the rapid development of the economy, centralized states (such as France, the United Kingdom, Spain) are being formed and strengthened, thus creating the necessary conditions for future trade expansion and industrial development.

The beginnings of industrial development and commercial expansion, interdependent with each other, led to the need to find new transport routes, shorter and safer, thus resulting in great geographical discoveries and thus laying the foundations of world trade. Also, the newly discovered territories led to conquests and colonisations, forming empires and accumulating resources necessary for the further growth of welfare in society, even if the main distribution took place at the level of the bourgeoisie and the nobility.

Economic changes and those of the social structure, in parallel with the increase of welfare in certain areas, determine the emergence of modern nation-states, along with the American and French Revolutions. These forms of government corresponded better to the interests of the development of economic relations, social ascension, and the welfare and prosperity of the bourgeoisie. This new system was attractive for those who wanted to prosper on a social scale, but also for those for whom European systems (and violent manifestations materialized in wars of colonization and expansion) were too expensive for national resources. In fact, France and the United States were areas of prosperity, either because of the resources in the colonies and their wider distribution through public services, or through the US Land Law, which allowed land in unexplored and unreviewed areas in the Wild West, within a maximum area of 160 acres to be used by owners as a farm (Homestead Act; US Congress 1862), which led to increased European immigration to the United States.

\section{Evaluating evolution as research objective}

The emergence of nation-states had an effect at the political level, necessary for its existence, namely the denial of the divine character of state power, thus recognizing a secular vision of the evolution of society and reformulating the relationship between society, state and individual, through what is called at the academic level: the social contract presented and developed by Alexis de Tocqueville in the book "On Democracy in America" [5].

This social state (of optimism and confidence in human possibilities to develop and live in peace and well-being), economic (generalization of an unexpected well-being in previous centuries) and political (marked by a healthy and stable hierarchy, which allowed smooth evolution in to the detriment of revolutions and conflicts at the level of often unmeritocratic elites) has led to a cultural advance under us and various unprecedented forms. In this context appear the humanists who created and promoted a new culture based on reason " thus overcoming the cultural limits imposed in the Middle Ages and putting man at the center of the new culture and social, economic and political interest. Thus a "spiritual" renaissance "is achieved, based on the revival of ancient Greco-Roman culture" (being promoted the idea of the dignity of the human being "as a free, autonomous, creative being", contrary to the pessimistic Christian conception of man and his damned nature: "as a creature Therefore, accepting the idea of the good nature of man, they praised humanistic culture and studies "as a means of ennobling and perfecting man, formulating the ideal of a multilateral development of the personality, of the universal man, embodied in the figure of the titans of creation and action ", thus promoting the critical spirit and the superior reason of faith and tradition; which determined a strong impetus of modern natural sciences based on the Newtonian principle of cause and effect, on the affirmative value of experiments / experiments and on the application of mathematics, which benefits from a period of development. 
In this social, economic and political context, the invention of the European printing press in 1439 and its wide spread in the second half of the 15th century will lead to an unprecedented development of mass media, being published in the first half of the century (more than 8 million volumes) more books than in the last thousand years.

The next evolution in distance communications (telegraph) leads to an increase in human mobility, by reducing the fear of the unknown and by informing about more attractive economic prospects, leading to an increase in human wealth and well-being and finally to the need for human emancipation. Thus, by increasing the number of people reading, at the level of the bourgeoisie, is meant the advantages of investing in human capital (especially in public primary education) for the future positive returns of companies. Adam Smith also notes in his book The Wealth of Nations the principle of the division and specialization of labour in various fields in a needle factory, thus reducing the cost of education to the bare necessities and making the investment in education efficient and attractive to the capitalist, that is primary public as a form of pre-selection and in differentiated training / apprenticeship for employees.

The development of radio and the telephone allowed on the one hand the humanization of the voice at the end of the wire (in the case of the telephone), the sender of the message thus acquiring an emotional character for the receiver, on the other hand, through cultural radio programs, stories and short stories in audio format) an education was achieved among the listening population both intellectually (by learning new information and experiences) and emotionally (by giving those messages an emotional character like a phone message from a relative). All this has led to the wide spread of the humanist vision, being helped by the continuous development of human well-being.

\subsection{The Black Lives Matter movement}

This civic movement emerged in 2012 at the time of the scandal caused, as today, by the death of a person of color, the teenager Trayvon Martin, fatally shot in Florida by a vigilante, a guard who was later, in 2013, acquitted. Some likened BLM to the Black Panthers. Nothing in common there except Black in name [6]. The Black Panthers emerged in 1966 as a radical alternative to the civic movement of people of colour. Those, the Black Panthers, were then a completely new phenomenon, and in California, because the law allowed it, they paraded armed. In general, however, they watched the police cars on the face, and when an arrest took place they would stand nearby and watch, making the police feel constantly watched.

Black Lives Matter do the same thing today, half a century later. Today, however, they do not demonstrate with weapons in sight, but with the mobile phone with which they film and keep evidence of abuse [6]. They did it in 2016, in Baton Rouge, Louisiana, where they filmed the shooting death of a young man of colour by two white police officers, following a dispute in the street.

The movement is diffuse, non-hierarchical, led virtually only by women, and refuses to approach institutionalized figures, such as Pastor Jesse Jackson. Through happenings and flash mob actions, BLM seeks to mobilize public opinion on issues related to minority rights or social issues, such as the minimum wage.

The paradox is that to some extent BLM even advocates for the improvement of the role of the police, which, in many disadvantaged urban areas, has become a mere administrator of poverty and racialism [6]. 


\subsection{The LGBT movement}

LGBT people enjoy the same human rights as all other people, rights that include the exercise of non-discrimination. The principle is enshrined in numerous international instruments, which provide for a wide field of application. Specifically, at the global level, it is set out in Article 26 of the International Covenant on Civil and Political Rights (ICCPR) and Article 2 of the International Covenant on Economic, Social and Cultural Rights (ICESCR) [7].

At the UN General Assembly in December 2008, the EU unanimously supported the Declaration on Human Rights, Sexual Orientation and Gender Identity, supported by 68 states on five continents [6]. The declaration reaffirms the principle of non-discrimination and condemns executions, arbitrary detention or human rights violations on the grounds of sexual orientation or gender identity.

Discrimination is the most common problem that LGBT people in most countries face on a daily basis because of their sexual orientation or gender identity. Discriminatory practices can be encountered in the workplace and in the public domain, especially with regard to access to medical services and education. Such practices violate the right to equality and non-discrimination in the exercise of human rights, as provided for in Articles 2 and 26 of the International Covenant on Civil and Political Rights (ICCPR) and Article 2 of the International Covenant on Economic, Social and Cultural Rights (ICESCR) [7].

\subsection{Corruption and anti-corruption}

Another phenomenon is that of corruption being defined as "perverting or destroying integrity or fidelity in the performance of public duties through bribes or favours" [8]. This is another phenomenon in the underground economy, a socio-political-economic phenomenon with negative implications for a country. Corruption manifests itself in various fields, in various and complex forms and interactions, but dominates the fiscal and budgetary arena [9]. The phenomenon can be observed in both developing and developed countries.

The main distinction to be made between tax evasion and corruption is: "although tax evasion may include bribing an official, tax evasion itself is the act of the private economic agent and does not necessarily involve public sector officials" [9].

In one of his works, Braşoveanu [9], listed three forms of corruption from the point of view of fiscal policies:

1. corruption in the collection of public financial (or fiscal) resources;

2. corruption in the distribution of budget expenditures;

3. corruption in quasi-fiscal activities (such as privatizations).

In this context, tax evasion and corruption are two important components of the underground economy, phenomena that have led to the degradation of the economy and society [10]. Combating them has become a priority in most states, where their negative impact is becoming increasingly known. However, curbing these phenomena has become all the more difficult as the underground economy has evolved from one period to another [9].

\section{The method of analysing the individual's identity}

Individual identity is based on a complex series of elements, among which are: the need to belong to a group; the norms, values, ideals and goals of the individual; and the usefulness 
of identity (obtaining benefits: social as a status within the hierarchy; psychological, pride, happiness and peace, with physiological effects; economic and access to public goods and resources) [11].

The norms or theoretical mode of behaviour accepted by the group are defined as a function that involves a specific social context and the adjustments of the application of these norms, made and accepted by the group in the case of each individual member. Values are a series of moral norms based on which the individual guides his actions and integrates into a group. Ideals and goals represent a vision of the individual over a certain period of time (defined or not) in the future, in the context of resources owned or estimated and in belonging to a group that allows (or in which a change can be predicted that will allow) or supports the achievement of that goal.

The identity of the individual, in which is found, among others, the system of norms and values, goals and ideals, determines the choice of tastes and motivates a certain specific type of consumption with effects on the general economy, but which can also have effects on cultural evolution and moral, political and social development of the group to which the individual belongs. Specialized studies have observed the potentiating effect of society on the development and success of an individual, and from an economic perspective it is reasonable to establish that an additional consumption of resources to convince the group of the fairness or efficiency of a behaviour, ideal, goal, vision, an effort or that of altering the identity of that group to assume, empower, support and / or integrate into the accepted value system that behaviour, ideal, goal or vision, will lead to a decrease in competitiveness in the short and medium term and to loss of energy that can be transposed into boosting the results of the effort itself [12]. However, if the group accepts those elements of identity as common elements and subsequently supports the efforts to achieve that goal, is strong or ideal, then the perception of an investment that can have a superimposed benefit / cost return and be sustainable, attracting individuals interested in However, from an economic perspective, identity is seen mainly from the perspective of non-market interests (but not only), including morality, social position or altruism, although the identity of a person who considers work moral will bring more benefits the economy and society as a whole, than an individual whose identity perceives work as something humiliating, a punishment, a mode of exploitation or slavery [13].

The thinker Adam Smith noted in the eighteenth century that a good society involves the exploitation of human passion and an effective social institutional framework that will have beneficial effects on the economy. His reasoning was based on the idea that man, being a social animal, especially in that period of relatively low mobility and with suboptimal resources due to the economic and social model approached, is directly influenced by the social environment in which he grows and develops to align as much as possible with the standards, norms and socio-cultural values of the community in which it is born in order to be accepted and in this way to be able to integrate into society, in order to maximize its benefits [14]. Thus, efficient social institutions allowed the development of economically efficient individuals, who respect and follow the group's values for their own well-being, and with direct consequences in general well-being, the optimal alternative to a series of individuals who do not respect social norms and had to be re-educated. Excluded from the company representing an unnecessary consumption of resources translated into a waste not allowed within that company [15]. Also, the pursuit of passions, activities for which the individual has long training or native talent has a lower cost for society and a decrease in costs that should compensate for the inconvenience caused by practicing the activity in question for the individual. 


\section{The research's findings and conclusion}

Modern economics begins with Adam Smith, who adapts the outdated and inefficient medieval moral philosophy of social science, which aimed at immediate social well-being in this physical world. Subsequently, the technical and mathematical development necessary for it, led to the emergence of mathematical models for the functioning of the economy, perpetuating the conception of Homo economicus, of a rational, economically motivated individual. In the twentieth century, economist Gary S. Becker [16] developed economic models that highlighted and demonstrated diverse, real (through demonstrations) and varied preferences.

With the advances made in research and development of psychology in recent decades, the economy of identity further humanizes the theoretical individual, bringing to its identity the social context (analyses discrimination, altruism, but also social constructs such as notions such as children, gender and race). It affects behaviour (rational from this point of view). Thus, motivation becomes a function of utility from a pecuniary perspective (income and consumption), as well as non-pecuniary (social status, family, fairness, reward).

The human need for fairness is represented by the reduction of work efficiency or efficiency due to demotivation when an unfair or unjustifiable distribution of resources obtained from work is observed, but also of resources in general and social benefits. In the historical context, the categorization and differentiation of people appeared due to insufficient resources. In books such as "History and Racism" or "A History of Childhood" [4] it is demonstrated on an argumentative basis how the social constructs called child and race appeared. If the separation between child and adult has been done more in the context of promoting humanistic ideals and economic interests (the prospect of a more efficient future exploitation with a higher total over a lifetime) in the general framework of society, the idea of race has been put in place. especially in the cultural context, initially involving religious differences, then economic interests through a more brutal exploitation of other races, in the context of the emergence of nation-states and the proclamation of human rights, especially for Europeans, rights that gave them acceptance in society and the possibility of leaving a group that offers minimal benefits, for a group that is willing to provide more satisfactory benefits.

In today's society we can talk about an emancipation of the individual as it has never been known in history. Social support (through public goods and universal transfers such as public health, free, universal and inclusive elementary education and social security) allows the individual to emancipate his needs and develop his identity function. In parallel, the globalization and widespread use of the Internet and digital social networks have allowed the comparison of the identity model in different societies, and, with its own emancipation and development of identity, to opt for testing and migration to other societies that would maximize identity utility to get the most out of group membership.

The value or usefulness of the identity is determined by the benefits it offers both within the reference group and in relation to other groups. If the benefits offered by another group are greater or more attractive than the initial group, theoretically, from an economic point of view, there will be the temptation to change the group, and implicitly the identity associated with the first group.

If it will be necessary to change your identity to join a different group with better perspectives and benefits, one or a series of transfer costs will appear. But if the newly obtained identity has benefits greater than or equal to the benefits of the original identity plus the costs of transfer then there are no impediments in achieving the change of identity.

Transfer costs can be cultural, social, ethnic, linguistic discrimination based on a different identity from the group, but even in these conditions the transfer can be beneficial, 
if the losses caused to the identity made by discrimination is lower in the new group than in the old one. For example, if a native of a group is socially and economically marginalized within that group, he may choose to belong to another group through emigration, change of religious faith, transfer from rural to urban areas or vice versa, and another form of discrimination may occur. on the basis of ethnicity or nationality (in case of emigration), on the basis of duration of group membership and lack of family tradition (in case of change of religion) or on the basis of language, values and / or behaviour (in case of change of social and economic environment). However, the benefits of the transfer are often greater, though not in all cases, either directly through the distribution of greater benefits or by maintaining the level of benefits distributed, but cumulated with a decrease in marginalization or discrimination, leading to thus a higher total than the existing situation in the initial group.

The identity of the individual and his reporting to the group can have major effects on the economy, as shown in the book "Animal Spirits" [17], in which the authors put the recessions or American panics in 1873, 1884, 1893, 1929, 1998 or 2008 resulting from withdrawals massive money supply or the sale of shares and real estate, due to the sudden reduction of confidence in the system and the correctness of other members of the group to be honest and fulfil their obligations as members of the group [18]. The economic implications of the identity of members of a group can also be seen at a broader level, that of various nations through emigration in the case of those who do not have confidence in future development and/or the perception of a system of equitable distribution of benefits within the group [19]. Those who have confidence in the future development and perception of a system of equitable benefit-sharing within the group, or where the final benefits minus transfer costs and discrimination are greater than those in the countries of emigration.

\section{References}

1. Valkenburg, P., Piotrowski, J. (2018). Generatia digitala si dependenta de media. Bucharest: Niculescu Publishing.

2. Alvesson, M., Willmott, H. (2002). Identity regulation as organization control: producing the appropriate individual. Journal of Management Studies, 39(5), 619-644.

3. Scherer, A., Palazzo, G. (2011). The new political role of business in a globalized world: a review of a new perspective on CSR and its implications for the firm, governance and democracy. Journal of Management Studies, 48(4), 899-931.

4. Heywood, C. (2017). O istorie a copilăriei: Copii în Occident, din Evul Mediu până în epoca modern. Bucharest: Trei Publishing.

5. Caldwell, N., Roehrich, J., George, G. (2017). Social value creation and relational coordination in public-private collaboration. Journal of Management Studies, 54(6), 906-928.

6. Alexe, D. (2020). Black Lives Matter: how the rembering of the segregation ignited the US movements. Free Europe. Retrieved from : https://moldova.europalibera.org/a/black-lives-matter-cum-amintirea-segregării-reiesela-suprafață-în-revoltele-din-sua/30644627.html.

7. European Union (2010). Promoting respect for all the fundamental rights of lesbian, gay, bisexual and transgender people. Europa.Eu. Retrieved from : https://www.consilium.europa.eu/media/32939/lgbt-qc3110646roc.pdf.

8. Oxford English Dictionary. Oxford Dictionaries. Retrieved from : https://en. https://en.oxforddictionaries.com/ 
9. Brasoveanu, I. V. (2010). Economia subterana si coruptia: probleme majore ale economiei romanesti. Theoretical and Applied Economics, 17(11), 68-80.

10. Habersang, S., Kuberling-Jost, J., Reihlen, M., Seckler, C. (2018). A process perspective on organizational failure: qualitative meta-analysis. Journal of Management Studies, 56(1), 19-56.

11. Ozalp, H., Cennamo, C., Gawer, A. (2018). Disruption in platform-based ecosystems, Journal of Management Studies. 55(7), 1203-1241.

12. Schotter, A., Mudambi, R., Doz, Y., Gaur, A. (2017). Boundary spanning in global organizations. Journal of Management Studies, 54(4), 403-421.

13. Shevchenko, A., Levesque, M., Pagell, M. (2016). Why firms delay reaching true sustainability, Journal of Management Studies. 53(5), 911-935.

14. Waldron, T., Fisher, G., Pfarrer, M. (2016). How social entrepreneurs facilitate the adoption of new industry practices, Journal of Management Studies. 53(5), 821-845.

15. Kohlhase, S., Pierk, J. (2020). The effect of a worldwide tax system on tax management of foreign subsidiaries. Journal of International Business Studies, 51, 1312-1330.

16. Becker, G. (1997). Capitalul uman. O analiza teoretica si empirica cu referire speciala la educatie. Iasi: All Publishing.

17. Akerlof, G., Shiller, R. (2010). Spirite Animale. Despre felul în care psihologia umană influenţează economia şi ce înseamnă asta pentru capitalismul global. Bucharest: Publica Publishing.

18. Cohen, B. (2016). The rise of alternative currencies. Journal of Management Studies, 54(5), 739-746.

19. Crossan, M., Byrne, A., Sejits, G., Reno, M., Monzani, L., Gandz, J. (2016). Toward a framework of leader character in organizations. Journal of Management Studies, 54(7), 986-1018. 